\title{
MODIFIKASI BAGIAN RANGKAIAN PENGUMPUL DAN MEJA POTONG PADA MESIN PEMANEN JAGUNG
}

\section{MODIFICATION OF HEADER PART AND CUTTER BAR ON CORN COMBINE HARVESTER}

\author{
Sony Harbintoro, Purnawan Nugroho, Martin Doloksaribu \\ Balai Besar Logam dan Mesin \\ Kementerian Perindustrian \\ Jalan Sangkuriang Nomor 12 Bandung \\ email : sonystrada@yahoo.com, mrtn.ds@gmail.com, purnawan.nugroho@yahoo.com
}

\begin{abstract}
Abstrak
Rangkaian pengumpul dan rangkaian meja potong pada mesin pemanen jagung dengan kombinasi (Combine Harvester) dilakukan modifikasi. Modifikasi mengacu kepada kinerja mesin pemanen padi dengan kombinasi pada model $\mathrm{CCH} 7130$ yang digunakan untuk memanen jagung. Mesin pemanen untuk padi tidak dapat langsung digunakan untuk melakukan pemanenan jagung sehingga diperlukan modifikasi dan penyesuaian. Karateristik lahan dan tanaman jagung dipelajari untuk mendapatkan modifikasi yang sesuai pada bagian rangkaian meja pengumpul dan meja potong. Modifikasi diimplementasikan pada sub komponen pengarah yang terdapat pada meja potong. Pada rangkaian pengumpul dilakukan penyesuaian ketinggian serta pengaturan arah kuku pengumpul. Uji coba kinerja pada desain rangkaian pengumpul dan meja potong untuk pemanenan jagung dianalisis. Setelah dilakukan modifikasi terjadi peningkatan produktivitas pemanenan jagung, dimana jumlah jagung yang jatuh ke tanah dari rangkaian pengumpul dapat berkurang. Bahasan ini diharapkan dapat menjadi contoh kasus bagi pengembangan atau modifikasi mesin pemanen padi menjadi mesin pemanen jagung untuk meningkatkan efisiensi dan produktivitas pada mekanisasi alat pertanian.
\end{abstract}

Kata kunci : mesin pemanen dengan kombinasi, pemanen jagung, modifikasi desain pengarah, modifikasi pengaturan kuku pengumpul.

\begin{abstract}
Header part and cutter bar on corn combine harvester are modified. Modification refers to the performance of a paddy combine harvesting machine of the CCH 7130 model that was used for harvesting corn. Combine harvesting machines for paddy can not be directly used for harvesting corn so that required modifications and adjustments. Characteristics of land and corn plants were studied to obtain appropriate modifications to the header part and cutter bar. Modifications are implemented on the referring sub component on the cutter bar. In the header part the elevation adjustment and the direction of the tines reel are adjusted. Performance trials on header part and cutter bar designs for corn combine harvester were analyzed. After modification there is an increase in corn harvesting productivity, where the amount of corn drop to the ground from the header part and cutter bar can be reduced. This discussion is expected to be a case study for the development or modification of paddy harvesting machine into a corn harvesting machine to improve efficiency and productivity in the mechanization of agricultural equipment.
\end{abstract}

Keywords : combine harvester, corn harvester, design modification of tine, setting modification of reel

\section{PENDAHULUAN}

Tanaman jagung adalah salah satu komoditas prioritas pemerintah selain padi dan kedelai. Seperti halnya pada komoditas padi, tahap pemanenan jagung merupakan tahap yang perlu diperhatikan untuk meningkatkan produktvitas jagung pipilan. Produksi jagung pipilan perlu ditingkatkan untuk menurunkan angka impor 
jagung (Kariyasa and M. Sinaga 2004). Peningkatan produktivitas dapat dicapai melalui penggunaan mesin pemanen (Djojowasito, Mustofa Ahmad, and Wicaksono 2002).

Mesin pemanen jagung tidak banyak digunakan oleh petani jagung di Indonesia. Namun beberapa petani jagung telah melakukan pemanenan jagung menggunakan mesin rice combine harvester. Saat ini mesin pemanen jagung kombinasi (corn combine harvester) memang belum tersedia. Mesin pemanen jagung yang digunakan saat ini merupakan hasil modifikasi dari mesin pemanen padi kombinasi (Harbintoro, Doloksaribu, and Nugroho 2016).

Mesin pemanen padi sudah tersedia di Indonesia sebelum mesin pemanen jagung dikembangkan. Mesin panen padi ini mengalami perkembangan dari teknologi yang sederhana sampai menjadi mesin pemanen padi kombinasi (combine rice harvester). Lutfi et al. (2002) telah melakukan rancang bangun mesin pemanen padi satu jalur. Bagian-bagian utama perancangan adalah motor penggerak, rangka, sistem transmisi penggerak pemotong dan roda penggerak.

Djojowasito (2002) telah melakukan pengujian terhadap mesin pemanen satu laju (one-row rice repaer) tersebut. Efektivitas pemotongan mampu mencapai 100 persen (Djojowasito, Mustofa Ahmad, and Wicaksono 2002).

Rahman (2016) melakukan rancang bangun dan uji teknis untuk alat perontok padi semi mekanis portabel. Hasil pengujian menunjukkan kapasitas perontokkan padi sekitar $26 \mathrm{~kg} / \mathrm{jam}$.

Mekanisasi panen pada padi memberikan beberapa keuntungan antara lain mampu menurunkan susut giling (Hasbullah and Dewi 2009).

Mesin pemanen padi telah berkembang menjadi mesin pemanen padi kombinasi (rice combine harvester). Mesin kombinasi memiliki fungsi yaitu memetik, merontokkan, memisahkan hasil perontokkan dengan biomassa dan menampung sementara hasil perontokan.

Mesin pemanen jagung telah mengalami perkembangan, dimulai dari teknologi sederhana sampai pada mesin pemanen jagung dengan kombinasi seperti yang terjadi pada mesin pemanen padi. Salah satu mesin pemanen yang telah tersedia adalah corn sheller dengan teknologi yang mampu memberikan keuntungan finansial bagi petani (Umar 2011). Penggunaan mesin pemanen jagung kombinasi dapat meningkatkan efektivitas pemanenan, baik waktu maupun kualitas jagung pipilan sehingga dapat meningkatkan produktivitas jagung pipilan. Hal tersebut juga memberikan keuntungan bagi petani jagung.

Mesin pemanen jagung kombinasi diperlukan oleh petani untuk meningkatan produktivitas jagung pipilan. Mesin corn sheller (pemipil jagung) dikembangkan menjadi corn combine harvester sehingga cakupan fungsi mesin menjadi semakin luas.

Harbintoro et al. (2016) telah melakukan penelitian terhadap kinerja header dari combine harvester yang dimodifikasi. Beberapa faktor yang mempengaruhi optimasi kinerja header yaitu tinggi pemotongan batang jagung, kecepatan putaran reel dan jarak ketinggian antara posisi reel dengan cutter bar (Harbintoro, Doloksaribu, and Nugroho 2016).

Salah satu kendala pada mesin rice combine harvester adalah grain losses (Bawatharani et al. 2015). Penelitian yang dilakukan Bawatharani et al. (2015) menyatakan bahwa grain losses dipengaruhi oleh pengaturan pada operasi reel pada bagian header. Nilai reel index yang lebih kecil menghasilkan grain losses yang lebih kecil. Reel index yang besar mengakibatkan impak yang besar antara tanaman dan reel. Nilai reel index dipengaruhi oleh kecepatan angular, radius reel dan kecepatan maju header. Parameter tersebut perlu disesuaikan terhadap karateristik tanaman dan lahan jagung.

Tujuan penelitian ini adalah untuk melakukan modifikasi pada rangkaian pengumpul dan meja pemotong pada mesin pemanen dengan kombinasi model CCH 7130 HORNET untuk meningkatkan efisiensi dan produktivitas pada proses pemanenan jagung.

Mesin pemanen padi yang akan digunakan untuk memanen tananam jagung memerlukan beberapa modifikasi yaitu, pada bagian header yang terdiri atas rangkaian pengumpul dan meja pemotong. Modifikasi dilakukan juga pada 
bagian trasnporter untuk membawa buah jagung ke pemipil (thresher). Kerapatan saringan (separator) pada bagian pembersih pun mengalami modifikasi mengingat ukuran biji jagung berbeda dengan ukuran bulir padi. Penelitian ini hanya membahas mengenai modifikasi bagian header yaitu modifikasi rangkaian pengumpul dan meja pemotong pada mesin pemanen padi dengan kombinasi model CCH 7130 HORNET.

\section{METODE PENELITIAN}

Penelitian dilakukan di Balai Besar Logam dan Mesin pada tahun 2016. Objek penelitian adalah mesin pemanen padi dengan kombinasi model CCH 7130 HORNET. Mesin tersebut diuji untuk memanen tanaman jagung. Hasil pengujian pada kinerja rangkaian pengumpul dan rangkaian pemotong dianalisis.

Survei lahan dilakukan untuk mempelajari dan mengamati karateristik lahan dan tanaman jagung. Hasil pengamatan menjadi acuan untuk melakukan modifikasi pada rangkaian pengumpul dan meja pemotong.

\section{Bahan dan Peralatan}

Bahan yang digunakan pada penelitian ini terdiri atas bahan baku dan bahan standar yang tersedia di pasaran. Pada Tabel 1 dan 2 diuraikan mengenai bahan baku dan bahan standar yang digunakan pada penelitian ini.

Tabel 1. Bahan baku utama yang digunakan untuk pabrikasi

\begin{tabular}{|c|c|c|c|c|}
\hline No & $\begin{array}{c}\text { Komponen/ } \\
\text { Bahan }\end{array}$ & Banyaknya & Bahan & Ukuran \\
\hline 1 & Pipa & 2 batang & galvanis & $1 / 4^{\prime} \times 6 \mathrm{~m}$ \\
\hline 2 & Plat & 2 batang & ST 37 & $150 \times 150 \mathrm{~mm}$ \\
\hline 3 & Cat & $1 \mathrm{~kg}$ & & \\
\hline 4 & Thiner & $4 \mathrm{lt}$ & & \\
\hline 5 & Tipoxy & $1 \mathrm{~kg}$ & & \\
\hline
\end{tabular}

Sumber : diolah peneliti

Tabel 2. Bahan standar yang digunakan

\begin{tabular}{|c|l|c|c|}
\hline No & \multicolumn{1}{|c|}{ Komponen } & Banyaknya & Ukuran \\
\hline 1 & Kawat las & $2 \mathrm{Kg}$ & $\varnothing 2,6 \mathrm{~mm}$ \\
\hline 2 & Batu gerinda tangan & $2 \mathrm{pcs}$ & 4 “ \\
\hline 3 & Batu cutting & $2 \mathrm{pcs}$ & 4 ” \\
\hline 4 & Mur dan Baut & $24 \mathrm{pcs}$ & M8 \\
\hline
\end{tabular}

Sumber : diolah peneliti
Peralatan yang digunakan untuk mendukung kegiatan penelitian ini dapat dilihat pada tabel 3 .

Tabel 3. Alat yang digunakan

\begin{tabular}{|c|l|c|c|}
\hline No & \multicolumn{1}{|c|}{ Alat/Mesin } & Spesifikasi & Ukuran \\
\hline 1 & Mesin las SMAW & $120 \mathrm{~A}$ & $\varnothing 2,6 \mathrm{~mm}$ \\
\hline 2 & Mesin gerinda tangan & $0,65 \mathrm{kw}$ & 4 “ \\
\hline 3 & Mesin bubut & & $300 \times 650 \mathrm{~mm}$ \\
\hline 4 & Mesin bor column & $3,7 \mathrm{kw}$ & M8 \\
\hline 5 & Meja kerja bangku & & \\
\hline 6 & Toolset & & \\
\hline 7 & Alat ukur & & \\
\hline
\end{tabular}

Sumber : diolah peneliti

\section{Tahapan penelitian}

\section{Persiapan pelaksanaan}

Untuk mendukung kelancaran pelaksanaan kegiatan modifikasi header pada mesin pemanen jagung tipe reel maka dilakukan persiapan-persiapan sebagai berikut:

1. Melakukan survei lapangan ke lahan tanaman jagung untuk mengetahui karakteristik topografi lahan sehingga desain pada bagian header dapat disesuaikan dengan kondisi lahan.

2. Melakukan konsultasi dengan tenaga ahli dari akademisi sebagai pembanding dalam mendisain modifikasi bagian header.

3. Membuat jadwal pelaksanaan kegiatan.

4. Menyiapkan bahan baku komponen pabrikasi dan bahan standar. Lihat Tabel 1 dan Tabel 2.

5. Membuat urutan proses pengerjaan dimulai dari gambar teknis, formulir work order sampai proses modifikasi.

Berikut pada Gambar 1 ditampilkan diagram alir penelitian. 


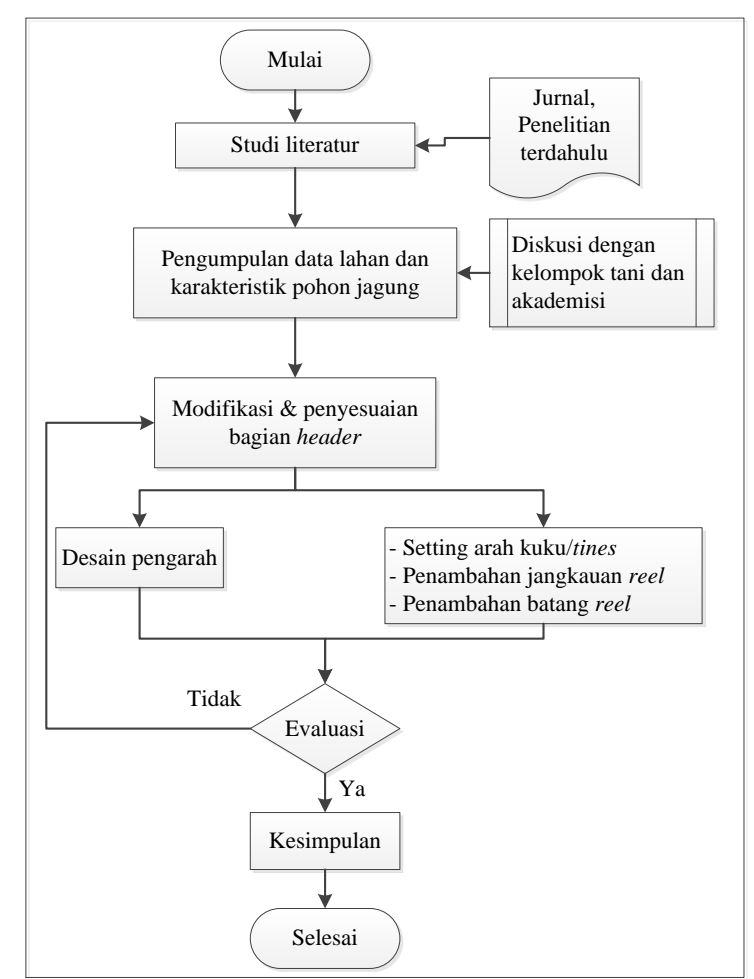

Gambar 1. Diagram alir penelitian

Sumber : Diolah peneliti

Modifikasi header pada mesin pemanen jagung tipe reel berkapasitas 0,34 ha per jam, secara garis besar dapat dibagi menjadi dua tipe pekerjaan, yaitu: pabrikasi pembuatan komponen dan pengaturan pada bagian reel. Untuk pekerjaan pengaturan reel tidak diperlukan gambar kerja, hanya ditentukan fungsi yang diinginkan dari komponen tersebut. Sedangkan untuk komponen fabrikasi dibuatkan gambar kerja, agar pembuatan peralatan tambahan dapat dipasang pada mesin pemanen jagung yang telah ada (existing). Gambar kerja terdiri atas gambar perakitan (assembling), sub perakitan (sub assembling) dan gambar detail.

Proses engineering: dibuatkan aliran proses pengerjaan, untuk setiap komponen pabrikasi mulai dari mesin yang digunakan, waktu pengerjaan, peralatan yang digunakan sampai alat bantunya, sehingga dapat dicapai mutu komponen yang diinginkan.

Pembuatan peralatan tambahan sebagai bagian dari modifikasi, dilakukan sesuai dengan proses engineering yang telah dibuat. Pengerjaannya dilakukan di workshop pemesinan dan pengelasan BBLM. Setelah semua komponen dibuat, dilakukan pelaksanaan perakitan (assembling).

Uji coba: dilakukannya untuk mengecek apakah peralatan tambahan yang dibuat dapat berfungsi sesuai dengan perencanaan.

\section{HASIL DAN PEMBAHASAN}

Mesin pemanen jagung kombinasi adalah mesin pemanen yang dapat melakukan beberapa tahapan proses sekaligus dalam satu mesin, yaitu proses : memotong, merontokkan dan membersihkan jagung. Mesin pemanen jagung kombinasi terdiri atas beberapa bagian utama yaitu bagian header meliputi bagian pengait dan pengarah (reel guider) yang disebut dengan rangkaian pengumpul, pemotong batang jagung (cutter bar) yang disebut rangkaian pemotong, pembawa hasil potongan tanaman jagung dan buah jagung (transporter), bagian perontok (thresher), bagian pembersih (separator), bagian pengeluaran batang, daun dan klobot jagung (chaff outlet), bagian penampung pipilan jagung (hopper), bagian pengeluaran hasil (grain outlet), bagian rangka kendaraan (main chassis), bagian hidrolik untuk mengatur ketinggian header, bagian engine, dan bagian pengendali (controller).

Mekanisme kerja mesin pemanen jagung kombinasi yaitu, tanaman jagung dikait dengan reel dan dipotong pada bagian batang pohon jagung dengan cutter bar, kemudian batang pohon jagung dan buah jagung dibawa oleh transporter ke bagian perontok (thresher) untuk dirontokan. Kemudian masukan semua bagian tanaman jagung (batang, daun, jagung, dan klobot) ke unit perontok untuk dirontokkan. Bagian sampah sisa hasil perontokan akan keluar melalui bagian pengeluaran sampah (chaff outlet). Pipilan jagung, dan kotoran kecil akan disalurkan ke bagian pembersih dengan mekanisme separator menggunakan kipas/blower yang dapat diatur kecepatan anginnya. Kotoran kecil akan keluar tertiup oleh kipas/blower sedangkan pipilan jagung akan masuk ke penampungan sementara (hopper) siap dimasukan ke dalam karung.

Diagnosis kinerja header pada kondisi mesin pemanen existing yaitu mesin pemanen untuk tanaman padi. Mesin pemanen padi ini karena dipergunakan untuk memanen padi, maka 
diperlukan beberapa penyesuaian dan modifikasi agar bisa digunakan untuk memanen tanaman jagung.

Diagnosis fungsi header pada kondisi existing, dilihat dari fungsi header dalam proses panen tanaman padi dan tanaman jagung, maka dilakukan modifikasi terhadap bagian header dengan menyesuaikan kondisi dan karaketeristik tanaman jagung. Header yang terpasang pada kondisi existing mesin pemanen $\mathrm{CCH} 7130$ HORNET adalah untuk tanaman padi.

Berdasarkan karaktersistik tanaman jagung maka beberapa modifikasi dan pengaturan dilakukan pada bagian sub assy pengarah, reel serta pengaturan posisi reel.

Tinggi tanaman jagung hibrida (bukan jagung manis) tergantung dari jenis varietas tanaman jagung yang ditanam. Pada bagian header terutama reel, ketinggian tanaman jagung dari tanah sampai ujung batang sangat mempengaruhi kinerja reel sehingga pengaturan posisi ketinggian reel pada header harus dilakukan. Fungsi reel pada unit header adalah untuk memegang tanaman agar dapat dipotong oleh cutter bar.

Pada bagian reel, sebelum dilakukan modifikasi terpasang empat set reel bar. Pada penelitian sebelumnya, jumlah reel bar yang dipasang menjadi tiga set. Saat dilakukan pengujian, dari pengamatan secara visual dan perhitungan kecepatan laju kendaraan dengan kecepatan putaran reel, diketahui bahwa jagung yang dapat diraih oleh reel bar lebih sedikit daripada saat digunakan keempat batang reel bar, sehingga jumlah reel bar yang dipasang dikembalikan menjadi empat batang.

Bagian lain yang dimodifikasi yaitu pada bagian pengarah. Letak pengarah berada pada bagian depan unit header yang berfungsi untuk mengatur dan mengarahkan batang tanaman untuk dipotong oleh cutter bar. Pada kondisi existing saat mesin ini dipergunakan untuk memanen padi, dimensi pengarah lebih pendek seperti dilihat pada Gambar 2 .

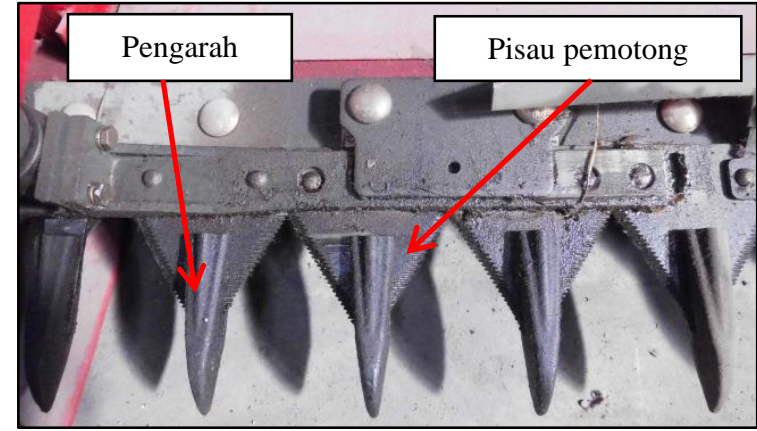

Gambar 2. Bentuk pengarah pada mesin existing sebelum modifikasi

Sumber : Diolah peneliti

Modifikasi pada bagian pengarah dilakukan melalui tiga iterasi percobaan pemasangan desain pengarah yang paling sesuai dengan karakteristik tanaman jagung dan kondisi lahan yang mempunyai gundukan-gundukan. Iterasi pertama, bagian pengarah dibuat dengan menggunakan material plat strip dengan tebal 3 $\mathrm{mm}$ yang dilengkapi dengan bagian penguat pada dudukan pengarah.

Iterasi desain konsep untuk pengarah yang pertama ditunjukan pada Gambar 3 .

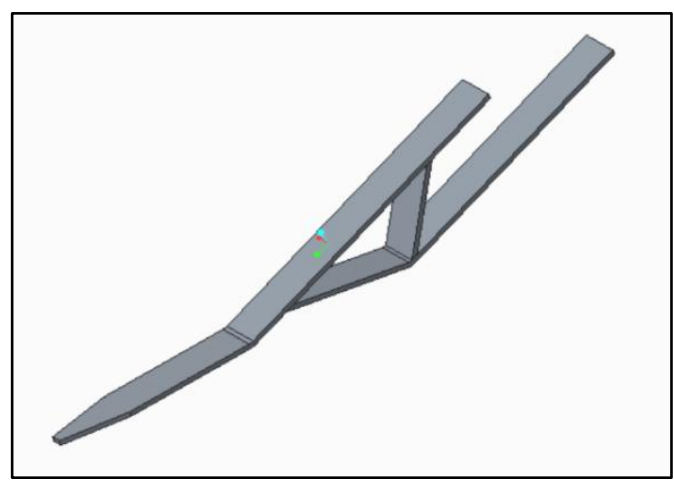

Gambar 3. Percobaan pertama desain pengarah dengan menggunakan plat strip

Sumber : diolah peneliti

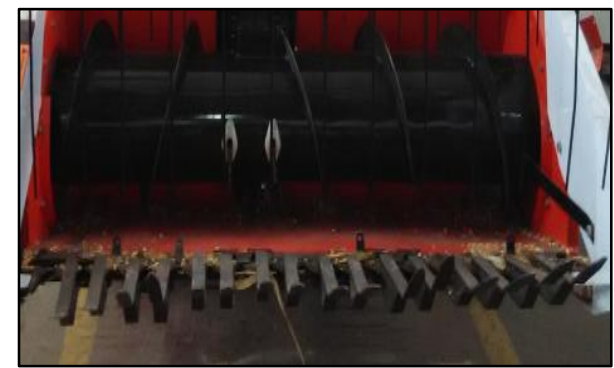

Gambar 4. Pengarah dengan plat strip yang terpasang pada header mesin pemanen jagung

Sumber : diolah peneliti 
Pada modifikasi/iterasi pertama menggunakan material plat seperti terlihat pada Gambar 4, pengarah dipasang pada dudukan yang sama dengan dudukan pengarah yang ada, sehingga pada assembly terdapat dua pengarah, dengan pengarah lama sekaligus berfungsi sebagai pisau diam. Pada saat dilakukan pengujian di lahan jagung, pengarah baru ini tidak memiliki kekuatan untuk menahan beban ketika mesin menabrak gundukan tanah. Pengarah baru ini menjadi bengkok dan cenderung dapat mengganggu kinerja pisau pemotong.

Dari hasil pengujian terhadap modifikasi pertama, kemudian dilakukan modifikasi kedua dengan membuat pengarah baru menggunakan material pelat dengan tebal $3 \mathrm{~mm}$ yang dibuat dua lapis yang diperkuat dengan stiffener. Berikut pada Gambar 5 ditampilkan desain pengarah kedua.

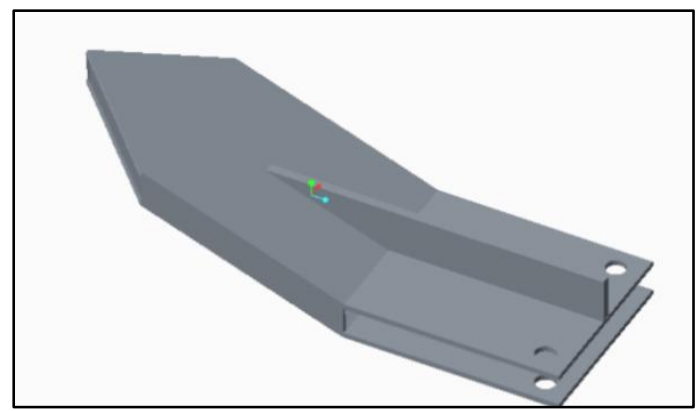

Gambar 5. Desain pengarah hasil modifikasi kedua

Sumber : diolah peneliti

Pemasangan pengarah ini menggunakan dudukan pengarah lama, sehingga pengarah yang orisinil harus dilepas untuk diganti dengan pengarah baru ini. Pengarah orisinil selain berfungsi sebagai pengarah berfungsi juga sebagai pisau diam, maka pengarah yang baru ini harus mempunyai fungsi yang sama. Dari hasil pengujian, terdapat beberapa kendala pada desain pengarah yang kedua ini. Kendala yang ditemukan di lapangan yaitu sulitnya pemasangan pengarah baru pada dudukan pengarah lama dikarenakan plat yang digunakan terlalu tebal. Permasalahan lainnya yaitu fungsi pengarah sebagai pisau diam tidak berfungsi dengan baik sehingga cutter bar tidak mampu memotong batang tanaman jagung.

Dari hasil pengujian terhadap modifikasi pertama dan kedua, kemudian dilakukan modifikasi ketiga dengan membuat pengarah baru menggunakan material pipa galvanis yang dipasangkan pada kuku lama dengan sambungan las, sehingga menjadi lebih panjang. Kuku modifikasi ini panjangnya dibuat sampai sejajar dengan reel bar sehingga selain berfungsi sebagai pengarah, juga sekaligus berfungsi sebagai penangkap biji jagung yang terlepas dari batang ketika dipegang oleh reel.

Material yang digunakan adalah pipa galvanis diameter $1 / 4$ inch yang berfungsi sebagai pengarah dan dapat menahan beban ketika menabrak gundukan tanah yang ada di lahan jagung.

Pada Gambar 6 berikut ditampilkan gambar desain 2D untuk pengarah dengan material dari pipa galvanis.

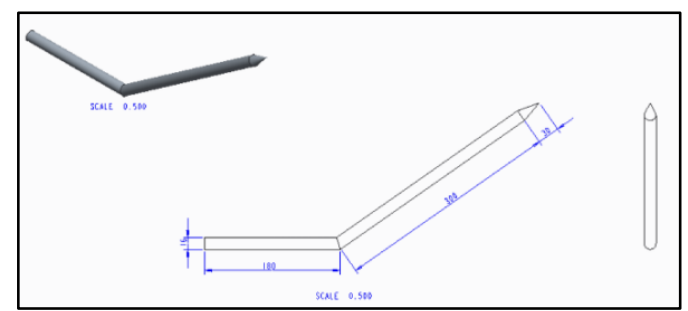

Gambar 6. Sub Assembly 2D bagian pengarah Sumber : diolah peneliti

Sedangkan pada Gambar 7 berikut ditampilkan gambar 3D sub assembly bagian pengarah.

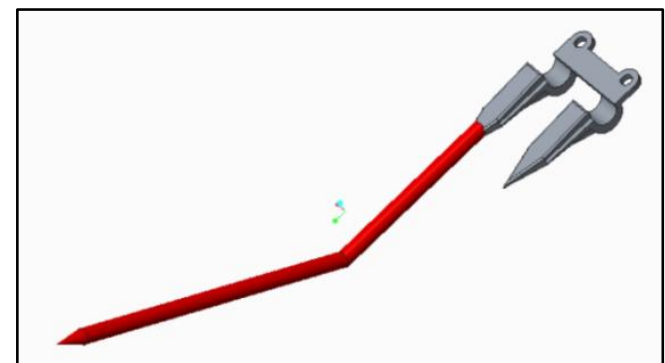

Gambar 7. Sub Assembly 3D bagian pengarah Sumber : diolah peneliti

Pada saat dilakukan pengujian di lahan jagung, kuku hasil modifikasi terakhir ini sesuai dengan rencana. Bagian pengarah dapat menahan beban yang terjadi ketika mesin menabrak gundukan tanah. Disamping itu, fungsi sebagai pengarah dan penangkap biji jagung juga lebih maksimal. Pengujian di lahan jagung daerah Cicalengka Kab. Bandung, buah jagung yang terjatuh ke tanah pada proses panen sangat sedikit. Kondisi ini terjadi karena jagung yang terlepas, ketika batang dikait oleh reel dapat ditangkap oleh pengarah yang 
panjang ini, seperti terlihat pada Gambar 8 . Gambar ini yang menunjukkan bagian pengarah terpasang pada header mesin pemanen jagung.

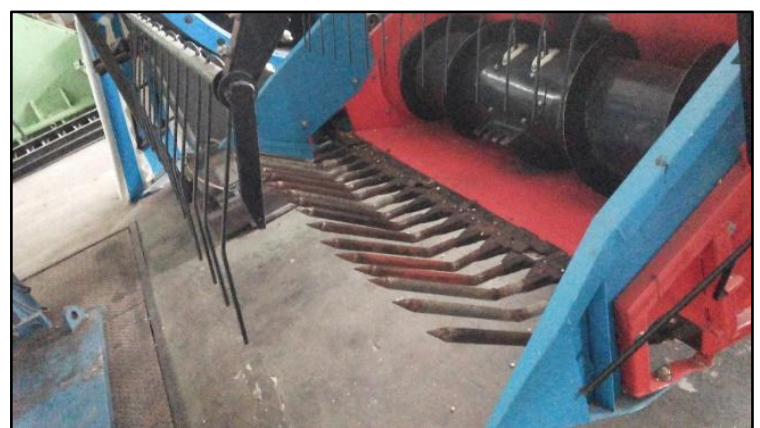

Gambar 8. Pengarah hasil modifikasi yang terbuat dari material pipa galvanis.

Kondisi mesin pemanen jagung di lahan jagung setelah dilakukan modifikasi pada bagian header khususnya pada rangkaian pengumpul dan meja potong dapat terlihat pada Gambar 9.

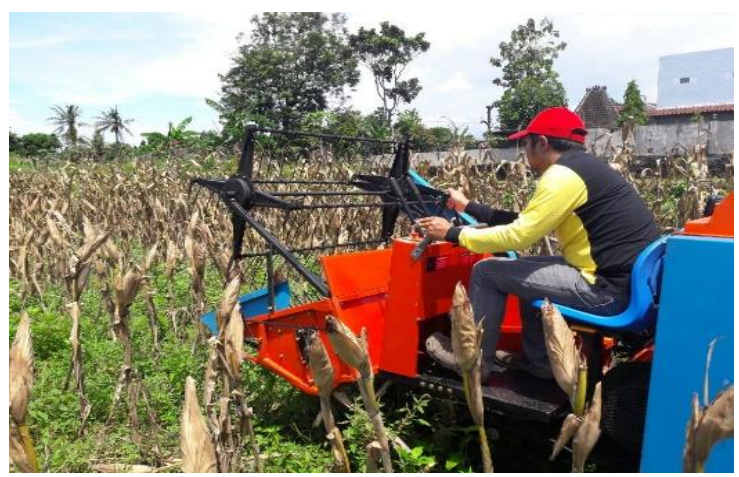

Gambar 9. Pengujian mesin pemanen jagung setelah modifikasi.

Proses pengujian lapangan terhadap mesin pemanen jagung padi yang telah dimodifikasi menjadi mesin pemanen jagung, dilaksanakan di Desa Manis Renggo, kecamatan Prambanan kab. Klaten. Pada Gambar 10 dapat terlihat pipilan jagung hasil panen saat pengujian lapangan dilahan jagung menggunakan mesin pemanen jagung hasil modifikasi.

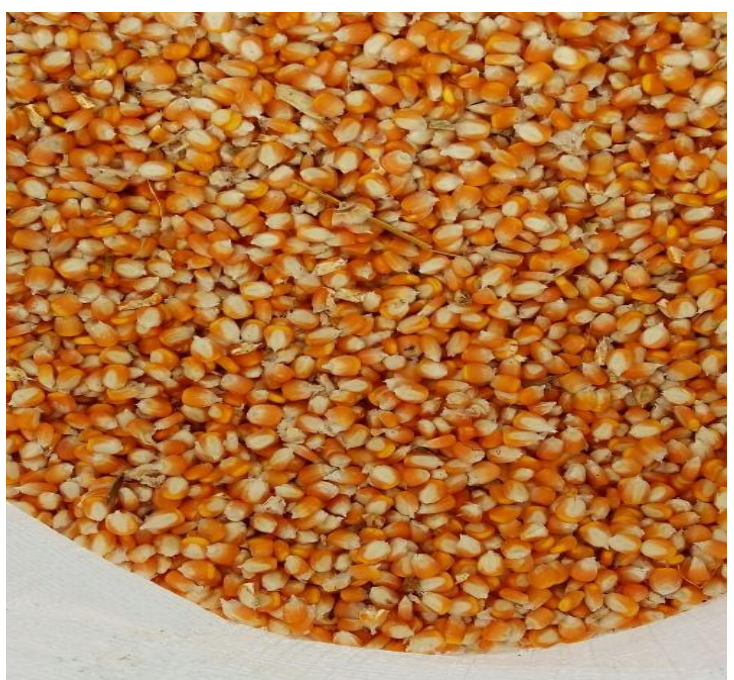

Gambar 10. Jagung pipilan hasil panen dari mesin pemanen jagung yang telah dimodifikasi.

\section{KESIMPULAN}

Berdasarkan hasil modifikasi rangkaian pengumpul dan meja pemotong terhadap mesin pemanen padi yang diubah menjadi mesin pemanen jagung maka didapat beberapa kesimpulan sebagai berikut : (1) Dari percobaan, dapat disimpulkan bahwa pada rangkaian pengumpul/pengait di bagian header, jumlah reel yang paling optimal adalah empat batang. (2) Dari beberapa iterasi yang telah dilakukan untuk modifikasi bagian pengarah, modifikasi yang paling optimal yaitu modifikasi menggunakan material pipa galvanis, karena dapat menahan beban yang terjadi ketika mesin menabrak gundukan tanah. Di samping itu, dimensi pengarah yang panjang selain berfungsi sebagai pengarah, juga berguna untuk menangkap buah jagung yang terlepas ketika batang dikait oleh reel sehingga panen menjadi lebih efisien.(3) Ketinggian reel disesuaikan terhadap ketinggian pengarah dngan mengacu pada ketinggian tanaman jagung yang akan dipanen untuk mengoptimalkan fungsi pengait.

\section{UCAPAN TERIMA KASIH}

Ucapan terima kasih kepada BBLM khususnya rekan-rekan staf sinlas dan rantek yang telah membantu memfasilitasi proses pengumpulan data. Bapak Dr. Ir. Hafid Abdullah, MT. yang telah membantu dalam penulisan karya tulis ilmiah serta Dr. Ir. Sri Bimo Pratomo, M.Eng. yang telah membantu menfasilitasi kegiatan ini. 


\section{DAFTAR PUSTAKA}

Bawatharani, R, D.N Jayatissa, D.A.N Dharmasena, and M.H.M.A Bandara. 2015. "Field Performance of a Conventional Combine Harvester in Harvesting Bg-300 Paddy Variety in Batticaloa, Srilanka." International Journal of Engineering Research 4 (1). Peradeniya, Sri Lanka: 33-35. http://www.ijer.in/ijer/index.php/explore/l ayout/issue-archive/volume-4/volume-4issue-1.

Djojowasito, Gunomo, Ary Mustofa Ahmad, and Ronny Wicaksono. 2002. "Pengujian Mesin Pemanen Padi Satu Lajur." Jurnal Teknologi Pertanian 3 (1). Malang, Indonesia: Fakultas Teknologi Pertanian Universitas Brawijaya: 9-12. http://jtp.ub.ac.id/index.php/jtp/article/vie w/132/496.

Harbintoro, Sony, Martin Doloksaribu, and Purnawan Nugroho. 2016. "Kinerja Header Pada Mesin Pemanen Jagung Tipe Reel." Jurnal Metal Indonesia 38 (1). Indonesia, Bandung. www.jurnalmetal.or.id.

Hasbullah, Rokhani, and Anggitha Ratri Dewi. 2009. "Kajian Pengaruh Konfigurasi Mesin Penggilingan Terhadap Rendemen Dan Sudut Giling Beberapa Varietas Padi." Jurnal Keteknikan Pertanian 23 (2). Bogor, Indonesia: Perhimpunan Teknik Pertanian Indonesia (PERTETA): 119-24.

http://journal.ipb.ac.id/index.php/jtep/artic le/view/7363/5716.

Kariyasa, Ketut, and Bonar M. Sinaga. 2004. "Faktor-Faktor Yang Mempengaruhi Perilaku Pasar Jagung Di Indonesia." Jurnal Argo Ekonomi 22 (2). Bogor, Indonesia: Pusat Sosial Ekonomi dan Kebijakan Pertanian (PSEKP): 167-94. http://ejurnal.litbang.pertanian.go.id/index .php/.

Lutfi, Musthofa, Gunomo Djoyowasito, Ekoyanto Pudjiono, and R. Fery Agung. S. 2002. "Rancang Bangun Mesin Pemanen Padi Satu Jalur." Jurnal Teknologi Pertanian 3 (1). Malang, Indonesia: Fakultas Teknologi Pertanian Universitas Brawijaya: 22-28. http://jtp.ub.ac.id/index.php/jtp/article/vie w/134/499.
Rahman, Mislaini. 2016. "Rancang Bangun Dan Uji Teknis Alat Perontok Padi Semi Mekanis Portabel." Jurnal Teknologi Pertanian Andalas 20 (1). Padang, Indonesia: Fakultas Pertanian Universitas Andalas:

$1-8$. http://tpa.fateta.unand.ac.id/index.php/JTP A/article/view/27/pdf_7.

Umar, Sudirman. 2011. "Teknologi Alat Dan Mesin Pasca Panen Sebagai Komponen Pendukung Usaha Tani Jagung Di Lahan Kering Kalimantan Selatan." Jurnal Agrista 15 (3). Kalimantan Selatan, Indonesia: Fakultas Pertanian Universitas Syiah Kuala Banda Aceh: 109-15. http://jurnal.unsyiah.ac.id/agrista. 